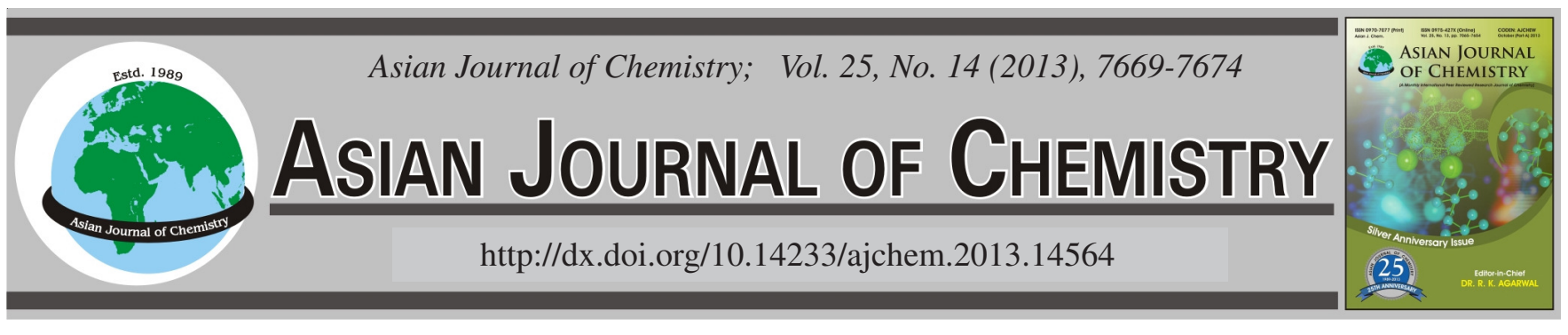

\title{
Synthesis and Characterization of Axially Linked Heteroleptic Polymeric and Monomeric Lewis Base Adducts of bis-(2-mercaptobenzothiazolato) Nickel(II) and Its Extraordinary Thermal Decomposition
}

\author{
M.S. SuRESH ${ }^{1, *}$ and M. PADMANABHAN ${ }^{2}$
}

${ }^{1}$ Department of Chemistry, Government Arts College, Udhagamandalam-643 002, India

${ }^{2}$ School of Chemical Sciences, Mahatma Gandhi University, Priyadarshini Hills, Kottayam-686560, India

*Corresponding author: E-mail: mssgacooty@gmail.com

Six coordinated axially bridged heteroleptic polymeric and monomeric Lewis base adducts from coordinatively unsaturated bis-(2mercaptobenzothiazolato) nickel(II) $\left\{\mathrm{Ni}(\mathrm{mbt})_{2},\left[\mathrm{NiC}_{14} \mathrm{H}_{8} \mathrm{~N}_{2} \mathrm{~S}_{4}\right]\right\}$ have been synthesized and charecterized by elemental analysis, spectral techniques, magnetic susceptibility measurements and thermal analysis using coordination sphere expansion method. These adducts have general molecular formula $\left[\mathrm{Ni}(\mathrm{mbt})_{2} \mathrm{~L}\right] \mathrm{n}$ for polymeric adducts and $\left[\mathrm{Ni}(\mathrm{mbt})_{2} \mathrm{~L} *_{2}\right]$ for monomeric adducts, where $\mathrm{L}=$ pyrazine, 4,4 bipyridine and 4,4'-azopyridine, $\mathrm{L}^{*}=$ pyridine and 4-amino pyridine. The infrared spectral studies suggested that 2-mercaptobenzothiazole is bidentate coordinating through its nitrogen and sulphur atoms. The bidentate Lewis bases used were capable to act as bridging ligand coordinated to two metal atoms which resulted into octahedral species with $\mathrm{MN}_{4} \mathrm{~S}_{2}$ chromophore but 4-aminopyridine is coordinating through its pyridyl nitrogen eventhough it was bidentate. The perceptible changes in the spectroscopic parameters like Dq, Nephelauxetic parameter $(\beta)$ and Racah parameter (B) of all adducts were evaluated and explained. The variation of magnetic behaviour on adduct formation was also studied. $\mathrm{Ni}(\mathrm{mbt})_{2}$ decomposes to yield $\mathrm{NiS}$, a stable residue with $\mathrm{Ni}(\mathrm{SCN})_{2}$ as one of the major intermediate but the adducts show an additional step due to the loss of Lewis bases leaving back the parent compound. The kinetic and thermodynamic parameters were also evaluated using Coats-Redfern equation. In most of the cases, it follows random nucleation, one nucleus on each particle obeying Mampel equation.

Key Words: Coordination sphere expansion, Lewis base adducts, 2-Mercaptobenzothiazolato nickel(II), Thermal studies.

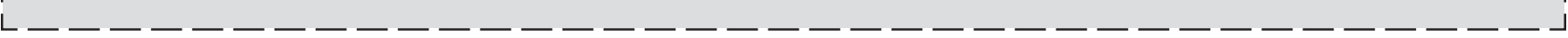

\section{INTRODUCTION}

One of the fascinating areas of coordination chemistry is the developing branch of coordination polymers with novel properties. For this purpose, coordinatively unsaturated systems-4-coordinate metal complexes can be subsequently linked with appropriate ligands resulted in new complexes with high coordination number. A few systems reported in this category involves macrocycles like phthalocyanines, porphyrins and substituted porphyrins as core ligating moieties with metal ions in its centre which on stacking generates linear chains through bridging ligands like-O-, -F- diatomic species like $\mathrm{CN}-,-\mathrm{C}=\mathrm{C}$ - and bidentate ligands like pyrazine, 1,4dicyanobenzene. The metals like Si(IV), Ge(IV), Sn(IV), $\mathrm{Fe}(\mathrm{II}), \mathrm{Fe}(\mathrm{III}), \mathrm{Mn}$ (III) and $\mathrm{Cr}(\mathrm{III})$ were used. This class of compounds are called Shiskabob polymers, have the ability to conduct electricity along the stacking axis. But all these are four coordinated systems with essentially $\mathrm{MN}_{4}$ chromophore with square planar geometry ${ }^{1-10}$.
As the earlier studies have focused on $\mathrm{MN}_{4}$ chromophores, it is pertinent to investigate on heterodentate chromophoric systems like $\mathrm{MN}_{2} \mathrm{~S}_{2}$. An interesting type of compound in this category would be four coordinated nickel(II) complex of 2-mercaptobenzothiazole $\mathrm{Ni}(\mathrm{mbt})_{2}$. There are many reports on the interaction of 2-mercaptobenzothiazole with various metals and their Lewis base adducts ${ }^{11,12}$ but concentrated only on monomeric adducts with pyridine, picolines, 1,10-phenanthroline etc. but their thermal studies were not conducted. In the present study attempts were made to develop axially bridged polymeric and some monomeric complexes of $\mathrm{Ni}(\mathrm{mbt})_{2}$ using bridging $\mathrm{N}$-bases with extensive conjugation.

\section{EXPERIMENTAL}

2-Mercaptobenzothiazole, pyridine, 4-aminopyridine, 4,4'-bipyridine, pyrazine, benzene, diethyl ether, $\mathrm{NiCl}_{2} \cdot 6 \mathrm{H}_{2} \mathrm{O}$ were either BDH or Merck samples. 4,4'-Azopyridine was prepared by oxidative coupling of 4-aminopyridine with 
hypochlorite using reported procedure ${ }^{13,14}$. The nickel contents in all the compounds were estimated by complexometric titration using murexide indicator. The $\mathrm{C}, \mathrm{H}$ and $\mathrm{N}$ analyses were carried out using Heracus $\mathrm{CHNO}$ rapid analyzer. The infra red spectra were recorded in the range $4000-400 \mathrm{~cm}^{-1}$ on a Shimadzu IR 470 spectrophotometer. Electronic spectra were recorded in the solid state using nujol mull paste employing a Shimadzu UV-160A spectrophotometer in the range 200-1100 $\mathrm{nm}$. The magnetic susceptibilities were measured on a Sartorious semimicro Gouy balance. The fields were calculated using a standard calibrant $\mathrm{Hg}\left[\mathrm{Co}(\mathrm{SCN})_{4}\right]$. The thermal analyses were carried out using either Seiko thermal analyzer or Delta Series TGA7 Thermal analyzer in an atmosphere of dry nitrogen with a heating rate of $10 \mathrm{~K} / \mathrm{min}$. The thermal decomposition features of all the complexes developed were studied and the thermodynamic and kinetic parameters calculated using a computer programme.

a) Synthesis of coordinatively unsaturated, four cordinated bis-(2-mercapto benzothiazolato) nickel(II), $\mathrm{Ni}(\mathbf{m b t})_{2}$ : A slightly modified method from the reported procedure was employed for its preparation. A solution of $\mathrm{NiCl}_{2} \cdot 6 \mathrm{H}_{2} \mathrm{O}(1.65 \mathrm{~g}, 0.01 \mathrm{~mol})$ in ethyl alcohol $(25 \mathrm{~mL})$ was added dropwise to a solution of $\mathrm{mbtH}(3.34 \mathrm{~g}, 0.02 \mathrm{~mol})$ in 100 $\mathrm{mL}$ ethanol while stirring. The dropwise addition of $5 \mathrm{M}$ ammonia (or very dilute $\mathrm{NaOH}$ ) solution precipitated the brown coloured complex. It was digested on a water bath for $1 \mathrm{~h}$ after which it was filtered, washed with water, ethyl alcohol followed by diethyl ether. It was then dried at $100{ }^{\circ} \mathrm{C}$ for $3 \mathrm{~h}$. Yield $90 \%$, $\mathrm{C}_{14} \mathrm{H}_{8} \mathrm{~N}_{2} \mathrm{~S}_{4} \mathrm{Ni}$, brown, (m.w. 391.24), Found (Calcd.) C 42.85 (43.0), H 2.02 (2.02), N 7.25 (7.20), Ni 15.15 (15.0).

\section{b) Synthesis of Lewis base adducts}

i) Pyridine adduct-[Ni(mbt $\left.)_{2}(\mathbf{p y r})_{2}\right]$ : One of the methods which was already reported in the literature was carried out in solution phase. But we are reporting a different solid-vapour phase reaction for its preparation. About $0.39 \mathrm{~g}(1 \mathrm{mmol})$ of $\mathrm{Ni}(\mathrm{mbt})_{2}$ was kept in a petridish in an air tight vessel. Then about $25 \mathrm{~mL}$ of pyridine was also kept in a beaker in the same vessel. The vapourized pyridine was seen reacting with the solid complex resulted into a green coloured complex after $24 \mathrm{~h}$. The unreacted pyridine was removed by keeping it at about $50{ }^{\circ} \mathrm{C}$ for $0.5 \mathrm{~h}$. Then it was washed with acetone and diethyl ether. The compound was then dried in vacuo. Yield was found to be $99 \% . \mathrm{C}_{24} \mathrm{H}_{18} \mathrm{~N}_{4} \mathrm{~S}_{4} \mathrm{Ni}$, green, (m.w. 549.17), Found (Calcd.) C 52.2 (52.0), H 3.20 (3.20), N 10.15 (10.2), Ni 10.80 (10.72).

ii) 4-Aminopyridine adduct $-\left[\mathrm{Ni}(\mathrm{mbt})_{2}(\operatorname{amp})_{2}\right]$ : $\mathrm{A}$ solution of 4-aminopyridine was prepared by dissolving $0.19 \mathrm{~g}$ ( $2 \mathrm{mmol}$ ) in $10 \mathrm{~mL}$ of acetone. This solution was added dropwise to a solution of $\mathrm{Ni}(\mathrm{mbt})_{2}(0.39 \mathrm{~g}, 1 \mathrm{mmol})$ in $10 \mathrm{~mL}$ of benzene. The reaction mixture was gently heated for about $15 \mathrm{~min}$ and then cooled. The precipitated compound was separated by filtration and then washed with acetone followed by ether. Yield $98 \% . \mathrm{C}_{24} \mathrm{H}_{20} \mathrm{~N}_{6} \mathrm{~S}_{4} \mathrm{Ni}$, green, (m.w. 579.24), Found (Calcd.) C 49. 7(49.72), H 3.45 (3.50), N 14.45 (14.40), Ni 10.10 (10.13).

iii) Pyrazine adduct, $\left[\mathrm{Ni}(\mathrm{mbt})_{2}(\mathrm{pyz})\right]_{\mathrm{n}}$ : A solution of pyrazine prepared by dissolving $0.12 \mathrm{~g}(1.5 \mathrm{mmol})$ in benzene was added to a solution of $\mathrm{Ni}(\mathrm{mbt})_{2}(0,39 \mathrm{~g}, 1 \mathrm{mmol})$ in $10 \mathrm{~mL}$ of benzene. The mixture was gently heated in a water bath for $0.5 \mathrm{~h}$. The greenish yellow coloured compound formed was repeatedly washed with benzene, acetone followed by diethyl ether. Yield $90 \% . \mathrm{C}_{18} \mathrm{H}_{12} \mathrm{~N}_{4} \mathrm{~S}_{4} \mathrm{Ni}$, greenish yellow, (m.w. 471.24), Found (Calcd.) C 45.82 (45.83), H 2.55 (2.54), N 11.90 (11.88), Ni 12.44 (12.45).

iv) 4,4'-bipyridine and 4,4'-azopyridine adduct, [Ni $(\mathbf{m b t})_{2}($ bipy $\left.)\right]_{\mathrm{n}}$, $\left[\mathrm{Ni}(\mathbf{m b t})_{2}(\mathbf{a z p y})\right]_{\mathrm{n}}$ : About $0.16 \mathrm{~g}(1 \mathrm{mmol})$ of 4,4'-bipyridine( $1 \mathrm{mmol}$ of 4,4'-azopyridine) dissolved in $10 \mathrm{~mL}$ of benzene was added to a solution of $1 \mathrm{mmol}$ of $\mathrm{Ni}(\mathrm{mbt})$. On slow cooling a green coloured compound was precipitated. The compound is purified by washing with benzene followed by ether. Yield $95 \%, \mathrm{NiC}_{24} \mathrm{H}_{16} \mathrm{~N}_{4} \mathrm{~S}_{4}$, green, (mol. wt. 547.17), Found (calcd.) C 52.61 (52.63), H 2.90 (2.94), N 10.30 (10.23), Ni 10.78 (10.72) and $\mathrm{C}_{24} \mathrm{H}_{16} \mathrm{~N}_{6} \mathrm{~S}_{4} \mathrm{Ni}$, (m.w. 577.24), orange, Found (Calcd.) C 49.82 (49.89), H 2.71 (2.79), N,14.60 (14.55), Ni 10.15 (10.16).

\section{RESULTS AND DISCUSSION}

Elemental analysis: The analytical data suggest that the adducts of pyrazine, 4,4'-bipyridine and 4,4'-azopyridine are polymeric with molecular formula $\left[\mathrm{Ni}(\mathrm{mbt})_{2} \mathrm{~L} *\right]$ while pyridine and 4-aminopyridine adducts were monomeric $\left[\mathrm{Ni}(\mathrm{mbt})_{2} \mathrm{~L}_{2}\right]$.

Infrared spectral data: 2-Mercaptobenzothiazole $(\mathrm{mbtH})$ is a potential bidentate ligand has a unique feature of having one $\mathrm{N}$ and two $\mathrm{S}$ atoms connected to a single carbon in a 5-membered heterocyclic moiety exist in two forms viz, thiol and thione ${ }^{15}$. In such a situation their coordination permits either through two $\mathrm{S}$ atoms or through $\mathrm{N}$ and exocyclic $\mathrm{S}$. But the reports on the interaction of 2-mercaptobenzothiazole with various metal ions as well as our studies suggested that the coordination is through nitrogen and sulphur ${ }^{11}$.

The IR absorption band at $3050 \mathrm{~cm}^{-1}$ which is assigned to $v(\mathrm{NH})$ in the $\mathrm{mbtH}$ is absent in $\mathrm{Ni}(\mathrm{mbt})_{2}$ indicates the deprotonation of the ligand. The thioamide band $\mathrm{v}(\mathrm{NCS})$ is known to occur at $1480 \mathrm{~cm}^{-1}$ (strong) was shifted to $1400 \mathrm{~cm}^{-1}$ and $v(\mathrm{C}=\mathrm{S})$ band at $667 \mathrm{~cm}^{-1}$ in the free ligand was shifted to $700 \mathrm{~cm}^{-1}$. These shifts in IR spectra of the complex indicate the chelation is through $\mathrm{N}$ and exocyclic $\mathrm{S}$ of the mbt moiety. The electronic spectrum of this complex in benzene shows three peaks at 25975,22220 and $16000 \mathrm{~cm}^{-1}$. The first peak could be assigned to CT while peaks at 22220 and $16000 \mathrm{~cm}^{-1}$ were due to ${ }^{1} \mathrm{~B}_{1 \mathrm{~g}} \rightarrow{ }^{1} \mathrm{~A}_{\mathrm{gg}}$ transition ${ }^{16}$ and the complex is diamagnetic. These are typical properties of square planar nickel(II) complexes.

The IR spectra of adducts showed the presence of characteristic peaks of Lewis bases and the peaks of mbt-shifted from their original position. The $v(\mathrm{~N}=\mathrm{C}=\mathrm{S})$ band at $1400 \mathrm{~cm}^{-1}$ was found to be shifted to $1385-1370 \mathrm{~cm}^{-1}$ and $v(C=S)$ band at $700 \mathrm{~cm}^{-1}$ was shifted to lower frequency $692-680 \mathrm{~cm}^{-1}$ in the adducts. The important stretching frequencies are given in Table-1. The $\mathrm{C}=\mathrm{C}$ and $\mathrm{C}=\mathrm{N}$ ring stretching skeletal bands in pyridine were observed in the range $1600-1430 \mathrm{~cm}^{-1}$ (4 peaks at $1440,1480,1580$ and $\left.1595 \mathrm{~cm}^{-1}\right)^{17}$. These bands are observed in the IR spectrum of all adducts except that of pyrazine. Upon complex formation the in-plane and out of plane ring deformations of pyridine moieties respectively at $604 \mathrm{~cm}^{-1}$ and $405 \mathrm{~cm}^{-1}$ were usually seen shifted to higher 
TABLE-1

IR SPECTRAL BANDS $\left(\mathrm{cm}^{-1}\right)$ OF Ni(mbt) ${ }_{2}$ AND ITS LEWIS BASE ADDUCTS

\begin{tabular}{lcccccccc}
\hline \multirow{2}{*}{ Compound } & $v(\mathrm{~N}=\mathrm{C}=\mathrm{S})$ & $v(\mathrm{C}=\mathrm{S})$ & ${ }^{\mathrm{a}} \mathrm{C}=\mathrm{C}+\mathrm{C}=\mathrm{N}$ & ${ }^{\mathrm{b}} v(\mathrm{C}=\mathrm{N})$ & ${ }^{\mathrm{c}} v\left(\mathrm{NH}_{2}\right)$ & $\delta(\mathrm{NH})$ & \multicolumn{2}{c}{ Ring deformation of pyridine } \\
\hline mbtH & 1480 & 667 & - & - & - & 1590 & - & Out of plane \\
$\mathrm{Ni}(\mathrm{mbt})_{2}$ & 1400 & 700 & - & - & - & - & - \\
{$\left[\mathrm{Ni}(\mathrm{mbt})_{2}(\mathrm{pyr})_{2}\right]$} & 1380 & 692 & $1590,1480,1445$ & - & - & - & 425 & - \\
{$\left[\mathrm{Ni}(\mathrm{mbt})_{2}(\mathrm{amp})_{2}\right]$} & 1385 & 685 & $1560,1505,1450$ & 1340 & 3480,3390 & 1622 & 422 & 635 \\
{$\left[\mathrm{Ni}(\mathrm{mbt})_{2}(\mathrm{pyz})\right]_{\mathrm{n}}$} & 1382 & 685 & - & - & - & - & - & - \\
{$\left[\mathrm{Ni}(\mathrm{mbt})_{2}(\mathrm{bipy})\right]_{\mathrm{n}}$} & 1380 & 685 & $1560,1530,1450$ & - & - & - & 420 & 685 \\
{$\left[\mathrm{Ni}(\mathrm{mbt})_{2}(\text { azpy })\right]_{\mathrm{n}}$} & 1370 & 682 & $1580,1560,1448$ & - & - & - & 420 & 680 \\
\hline${ }^{\mathrm{a}} \mathrm{C}=\mathrm{C}$ and $\mathrm{C}=\mathrm{N}$ stretching in pyridine, ${ }^{\mathrm{b}}$ non coordinated $v(\mathrm{C}=\mathrm{N})$ in aromatic primary amine, ${ }^{\mathrm{c}} v\left(\mathrm{NH}_{2}\right)$ of aromatic primary amine
\end{tabular}

frequencies ${ }^{17}$. These bands were observed in the range 680$635 \mathrm{~cm}^{-1}$ and $425-420 \mathrm{~cm}^{-1}$ respectively in adducts confirming the coordination of pyridyl nitrogen to metal.

The primary amines show two absorptions in the range $3500-3400 \mathrm{~cm}^{-1}$ due to asymmetric and symmetric N-H stretching modes and bending mode at $1650-1580 \mathrm{~cm}^{-1}$. These bands were observed at 3480,3390 and $1620 \mathrm{~cm}^{-1}$ in 4-aminopyridine adduct which was almost unaltered as compared to free ligand. This indicates the non coordination of $-\mathrm{NH}_{2}$ group on adduct formation ${ }^{18}$ and it was due to its resonance stabilization and planar structure.

It was found from the literature ${ }^{19-22}$ that if pyrazine is bonded to the metal only through one of its nitrogen shows a band in the region 1000-950 $\mathrm{cm}^{-1}$. But this band is generally absent if it is acting as bridging bidentate ligand leads to polymeric species and as a weak band in oligomeric species. The pyrazine molecule has a centrosymmetric ring stretch at about $1600 \mathrm{~cm}^{-1}$ which is IR and Raman allowed for unidentate pyrazine complexes but only Raman allowed for bidentate polymeric compounds. It was also reported that the bands present in pyrazine at 1230 and $695 \mathrm{~cm}^{-1}$ disappear on polymerization. The IR spectrum of pyrazine adduct shows a negligible absorption at $1590 \mathrm{~cm}^{-1}$ but with no peaks in the range $1000-950 \mathrm{~cm}^{-1}$ and $1230 \mathrm{~cm}^{-1}$ indicates its polymeric nature.

The monomeric compounds of bipyridyl ${ }^{6}$ show bands at $1589,1483,1402,1215,1070$ and $800 \mathrm{~cm}^{-1}$. The predominant spectral difference for monomeric and polymeric compounds is the disappearance of absorptions at about 1589, 1402 and $1215 \mathrm{~cm}^{-1}$. The IR spectrum of $\left[\mathrm{Ni}(\mathrm{mbt})_{2}(\text { bipy })\right]_{\mathrm{n}}$ contains new bands at 1480,1080 and $800 \mathrm{~cm}^{-1}$ and very very weak absorptions at 1600,1405 and $1215 \mathrm{~cm}^{-1}$ supports the polymeric nature of the adduct. If both pyridyl units are arranged in the same plane 4,4'-bipyridine is centrosymmetric to its 4,4' bond centre and the in plane vibration at $1215 \mathrm{~cm}^{-1}$ of monomeric species loses its IR activity and absent in polymeric dimeric compounds. The centre of symmetry disappears when pyridyl planes are tilted or acting as monodentate and making the peak at $1215 \mathrm{~cm}^{-1}$ is IR active. Since the elemental analysis, thermal analysis and other spectral data suggested that $\left[\mathrm{Ni}(\mathrm{mbt})_{2}(\text { bipy })\right]_{\mathrm{n}}$ is $1: 1$ polymeric adduct. Therefore the appearance of band at $1215 \mathrm{~cm}^{-1}$ indicates that the pyridyl groups are not in the same plane but tilted.

One of the very sensitive vibrations the thioamide II band $v(\mathrm{C}=\mathrm{N}=\mathrm{S})$ for $\mathrm{Ni}(\mathrm{mbt})_{2}$ appears at $1440 \mathrm{~cm}^{-1}$ but in all the adducts this is shifted significantly in the lower region by about
$15-30 \mathrm{~cm}^{-1}$. As the Lewis bases are strong sigma donors they would pump a lot of electron density on the central metal atom in adducts. This would in turn burden the metal with excess electron density. The only way the metal can relieve of the unwanted electron density is by pushing the electron density on the basal ligand which is in conjugation with metal which would strengthen $\mathrm{M}-\mathrm{C}$ bond but weaken $\mathrm{C}-\mathrm{S}$ bond. The net result would be the decrease in $v(C=N=S)$ and $v(C=S)$.

Electronic spectra: The electronic spectra of $\mathrm{Ni}(\mathrm{mbt})_{2}$ adducts show three absorption maxima in the range 700013000, 11000-20000 and 19000-27000 $\mathrm{cm}^{-1}$ (Table-2). These are characteristic of octahedral $\mathrm{Ni}$ (II) complexes and can be assigned to ${ }^{3} \mathrm{~A}_{2 \mathrm{~g}} \rightarrow{ }^{3} \mathrm{~T}_{2 \mathrm{~g}}(\mathrm{~F})\left(\mathrm{V}_{1}\right),{ }^{3} \mathrm{~A}_{2 \mathrm{~g}} \rightarrow{ }^{3} \mathrm{~T}_{1 \mathrm{~g}}(\mathrm{~F})\left(\mathrm{V}_{2}\right)$ and ${ }^{3} \mathrm{~A}_{2 \mathrm{~g}} \rightarrow$ ${ }^{3} \mathrm{~T}_{\mathrm{lg}}(\mathrm{P})\left(\mathrm{V}_{3}\right)$ transitions, respectively ${ }^{23}$. For octahedral Ni(II) complexes $V_{1}$ is directly taken as $10 \mathrm{Dq}$. The Racah parameter $\mathrm{B}^{\prime}$ can be calculated by using the equation

$$
\mathrm{B}^{\prime}=\left(\mathrm{v}_{2}+\mathrm{v}_{3}-3 \mathrm{v}_{1}\right) / 15
$$

The nephalauxetic parameter $\beta$ could be obtained by using the relation $\beta=\mathrm{B}^{\prime}$ (complex)/B(free ion), where $\mathrm{B}$ (free ion) is $1041 \mathrm{~cm}^{-1}$. The Dq value of pyridine adduct is smaller than that of 4-aminopyridine adduct. This could be due to strong ligating capacity of 4-aminopyridine $(\mathrm{pKa}=9.11)$ as compared to pyridine $(\mathrm{pKa}=5.17)^{24}$. The $\mathrm{Dq}$ and $\beta$ values of polymeric species is higher than that of monomeric one could be attributed to the extended $\pi$-conjugation of the orbitals of bidentate ligand and the metal ion in one dimension. Because of this $\pi$ bonding ability, the M-N bond can acquire some amount of double bond character which would increase their relative stability and covalent character. It is generally observed that for octahedral complexes the $v_{2} / v_{1}$ lies in the range 1.5-1.7.

Magnetic susceptibility measurements: The magnetic moments of these adducts were seen to be in the range 3.0-3.2 BM (Table-2) which are typical for octahedral nickel(II) complexes and also found that the polymeric adducts have lower values (3.01 BM) as compared to monomeric species.

Thermal studies: The TG/DTG curve of $\mathrm{Ni}(\mathrm{mbt})_{2}$ in nitrogen atmosphere shows two stage decomposition in which the first stage corresponds to the breakage of two bonds of the five membered heterocycle at $\mathrm{N}$ and $\mathrm{C}$ would yield $\mathrm{Ni}(\mathrm{SCN})_{2}$ as the residue ${ }^{25}$. The reported thermal stability of $\mathrm{Ni}(\mathrm{SCN})_{2}$ is upto $410{ }^{\circ} \mathrm{C}$ agrees well with our result. The second stage is due to the decomposition of $\mathrm{Ni}(\mathrm{SCN})_{2}$ to $\mathrm{NiS}$, a stable residue. The experimental mass loss in the thermogram is in close agreement with the theoretical calculated values (given in Table-3). The TG/DTG curves of Lewis base adducts are given in Figs. 1-5 show a three stage decomposition pattern. The first stage 
TABLE-2

ELECTRONIC SPECTRAL DATA AND MAGNETIC MOMENTS

\begin{tabular}{|c|c|c|c|c|c|c|c|}
\hline Compound & Absorption maxima & Assignments & $\mathrm{B}\left(\mathrm{cm}^{-1}\right)$ & $\operatorname{Dq}\left(\mathrm{cm}^{-1}\right)$ & $\mathrm{B}\left(\mathrm{cm}^{-1}\right)$ & $v_{2} / v_{1}$ & $\mu_{\text {eff }}(B M)$ \\
\hline$\left[\mathrm{Ni}(\mathrm{mbt})_{2}\right]$ & $\begin{array}{l}25975 \\
22220 \\
16000\end{array}$ & $\begin{array}{c}\mathrm{CT} \\
{ }^{1} \mathrm{~B}_{1 \mathrm{~g}} \rightarrow{ }^{1} \mathrm{~A}_{1 \mathrm{~g}} \\
{ }^{1} \mathrm{~B}_{1 \mathrm{~g}} \rightarrow{ }^{1} \mathrm{~A}_{1 \mathrm{~g}}\end{array}$ & - & - & - & - & Dia \\
\hline$\left[\mathrm{Ni}(\mathrm{mbt})_{2}(\mathrm{pyr})_{2}\right]$ & $\begin{array}{c}25445 \\
15850 \\
9300\end{array}$ & $\begin{array}{l}v_{3} \\
v_{2} \\
v_{1}\end{array}$ & 892.4 & 930 & 0.957 & 1.7 & 3.15 \\
\hline$\left[\mathrm{Ni}(\mathrm{mbt})_{2}(\mathrm{amp})_{2}\right]$ & $\begin{array}{c}25905 \\
16180 \\
9520\end{array}$ & $\begin{array}{l}v_{3} \\
v_{2} \\
v_{1}\end{array}$ & 901.0 & 952 & 0.866 & 1.69 & 3.14 \\
\hline$\left[\mathrm{Ni}(\mathrm{mbt})_{2}(\mathrm{pyz})\right]_{\mathrm{n}}$ & $\begin{array}{l}25250 \\
16390\end{array}$ & $\begin{array}{l}v_{2} \\
v_{1}\end{array}$ & - & - & - & - & 3.10 \\
\hline$\left[\mathrm{Ni}(\mathrm{mbt})_{2}(\text { bipy })\right]_{\mathrm{n}}$ & $\begin{array}{l}25575 \\
16390 \\
10520\end{array}$ & $\begin{array}{l}v_{3} \\
v_{2} \\
v_{1}\end{array}$ & 692.7 & 1052 & 0.665 & 1.56 & 3.01 \\
\hline$\left[\mathrm{Ni}(\mathrm{mbt})_{2}(\mathrm{azpy})\right]_{\mathrm{n}}$ & $\begin{array}{l}24630 \\
16130 \\
10320\end{array}$ & $\begin{array}{l}v_{3} \\
v_{2} \\
v_{1}\end{array}$ & 653.7 & 1032 & 0.628 & 1.56 & 3.02 \\
\hline
\end{tabular}

TABLE-3

THERMAL ANALYSIS DATA

\begin{tabular}{cccccl}
\hline Compound & Temp. range $\left({ }^{\circ} \mathrm{C}\right)$ & Peak temp. $\left({ }^{\circ} \mathrm{C}\right)$ & Stage & Mass $(\%)$ found (calcd.) & Probable reactions \\
\hline$\left[\mathrm{Ni}(\mathrm{mbt})_{2}\right]$ & $280-395$ & 327.78 & 1 & $53.0(55.35)$ & $\mathbf{1} \rightarrow \mathrm{Ni}(\mathrm{SCN})_{2}$ \\
$\mathbf{1}$ & $410-900$ & 562.34 & 2 & $23.75(21.47)$ & $\mathrm{Ni}(\mathrm{SCN})_{2} \rightarrow \mathrm{NiS}$ \\
& Above 900 & - & - & $23.25(23.18)$ & $\mathrm{NiS}(\mathrm{residue})$ \\
{$\left[\mathrm{Ni}(\mathrm{mbt})_{2}(\mathrm{pyr})_{2}\right]$} & $125-200$ & 174.8 & 1 & $28.10(28.75)$ & $\mathbf{2} \rightarrow\left[\mathrm{Ni}(\mathrm{mbt})_{2}\right]+2 \mathrm{pyr}$ \\
$\mathbf{2}$ & $280-350$ & 301.3 & 2 & $40.14(39.45)$ & $\left.\mathrm{Ni}(\mathrm{mbt})_{2}\right] \rightarrow \mathrm{Ni}(\mathrm{SCN})_{2}$ \\
& $350-600$ & 431.6 & 3 & $15.00(15.30)$ & $\mathrm{Ni}(\mathrm{SCN})_{2} \rightarrow \mathrm{NiS}$ \\
{$\left[\mathrm{Ni}(\mathrm{mbt})_{2}(\mathrm{amp})_{2}\right]$} & Above 600 & - & - & $16.77(16.5)$ & $\mathrm{NiS}(\mathrm{residue})$ \\
$\mathbf{3}$ & $200-270$ & 259.93 & 1 & $32.43(32.49)$ & $\mathbf{3} \rightarrow\left[\mathrm{Ni}(\mathrm{mbt})_{2}\right]+2 \mathrm{amp}$ \\
& $280-400$ & 327.78 & 2 & $32.42(37.39)$ & $\left(\mathrm{Ni}(\mathrm{mbt})_{2}\right] \rightarrow \mathrm{Ni}(\mathrm{SCN})_{2}$ \\
& $400-650$ & 562.34 & 3 & $19.37(14.50)$ & $\mathrm{Ni}(\mathrm{SCN})_{2} \rightarrow \mathrm{NiS}$ \\
{$\left[\mathrm{Ni}(\mathrm{mbt})_{2}(\mathrm{pyz})\right]_{\mathrm{n}}$} & Above 600 & - & - & $15.77(15.65)$ & $\mathrm{NiS}(\mathrm{residue})$ \\
$\mathbf{4}$ & $110-200$ & 184.95 & 1 & $17.2(16.98)$ & $\mathbf{4} \rightarrow\left[\mathrm{Ni}(\mathrm{mbt})_{2}\right]+\mathrm{pyz}$ \\
& $280-435$ & 331.34 & 2 & $42.19(45.96)$ & $\left.\mathrm{Ni}(\mathrm{mbt})_{2}\right] \rightarrow \mathrm{Ni}(\mathrm{SCN})_{2}$ \\
{$\left[\mathrm{Ni}(\mathrm{mbt})_{2}(\mathrm{bipy})\right]_{\mathrm{n}}$} & $435-650$ & 527.03 & 3 & $21.44(17.83)$ & $\mathrm{Ni}(\mathrm{SCN})_{2} \rightarrow \mathrm{NiS}$ \\
$\mathbf{5}$ & Above 650 & - & - & $19.17(19.24)$ & $\mathrm{NiS}(\mathrm{residue})$ \\
& $180-280$ & 203.07 & 1 & $29.09(28.51)$ & $\mathbf{5} \rightarrow\left[\mathrm{Ni}(\mathrm{mbt})_{2}\right]+\mathrm{bipy}$ \\
& $280-380$ & 284.61 & 2 & $33.09(39.57)$ & $\left.\mathrm{Ni}(\mathrm{mbt})_{2}\right] \rightarrow \mathrm{Ni}(\mathrm{SCN})_{2}$ \\
{$\left[\mathrm{Ni}(\mathrm{mbt})_{2}(\mathrm{azpy})\right]_{\mathrm{n}}$} & $380-550$ & 393.84 & 3 & $21.17(15.36)$ & $\mathrm{Ni}(\mathrm{SCN})_{2} \rightarrow \mathrm{NiS}$ \\
$\mathbf{6}$ & Above 550 & - & - & $16.64(16.57)$ & $\mathrm{NiS}(\mathrm{residue})$ \\
& $175-335$ & 303.67 & 1 & $32.87(32.22)$ & $\mathbf{6} \rightarrow\left[\mathrm{Ni}(\mathrm{mbt})_{2}\right]+\mathrm{azpy}$ \\
& $335-460$ & 410.80 & 2 & $29.97(37.52)$ & $\left.\mathrm{Ni}(\mathrm{mbt})_{2}\right] \rightarrow \mathrm{Ni}(\mathrm{SCN})_{2}$ \\
& $460-540$ & 498.68 & 3 & $21.16(14.55)$ & $\left.\mathrm{Ni}(\mathrm{mbt})_{2}\right] \rightarrow \mathrm{Ni}(\mathrm{SCN})_{2}$ \\
\hline
\end{tabular}

$\left(125-200{ }^{\circ} \mathrm{C}\right)$ is due to the braking of nickel-Lewis base $\mathrm{N}$ bond which eliminates two molecules from pyridine from $\left[\mathrm{Ni}(\mathrm{mbt})_{2}(\mathrm{pyr})_{2}\right]$ yielding back the four coordinate $\mathrm{Ni}(\mathrm{mbt})_{2}$ because the two additional $\mathrm{M}-\mathrm{N}$ bonds formed in the Lewis base adducts are different from the other four. The observed mass loss $(28.1 \%)$ is in good agreement with the calculated value $(28.75 \%)$. In the case of $\left[\mathrm{Ni}(\mathrm{mbt})_{2}(\mathrm{amp})_{2}\right]$ the mass loss in the first stage $32.43 \%$ is due to the elimination of two molecules of 4-aminopyridine. But only one molecule can be released from their polymeric adducts. The mass loss calculated $(16.98 \%)$ for the loss of one molecule of pyrazine from $\left[\mathrm{Ni}(\mathrm{mbt})_{2}(\mathrm{pyz})\right]_{\mathrm{n}}$ was in good agreement with the observed value $(17.2 \%)$. $\left[\mathrm{Ni}(\mathrm{mbt})_{2}(\text { azpy })\right]_{\mathrm{n}}$ and $\left[\mathrm{Ni}(\mathrm{mbt})_{2}(\text { bipy })\right]_{\mathrm{n}}$ also show the same behaviour. A well defined horizontal plateau after the first stage of decomposition in the range $200-280{ }^{\circ} \mathrm{C}$ supports the formation and thermal stability of $\mathrm{Ni}(\mathrm{mbt})_{2}$. The second and third stages are similar to the decomposition of $\mathrm{Ni}(\mathrm{mbt})_{2}$. Because of the non-volatile nature of the bridging ligand 4,4'-azopyridine its decomposition is not exactly similar to the other compounds. The mass loss and probable decomposition pattern of all the compounds are presented in Table-3.

Kinetic and Mechanistic aspects: The kinetic parameters for the thermal decomposition stages of the Lewis base adducts are calculated from the slopes and intercepts of linear plots using Coats-Redfern method ${ }^{26}$. The activation energies, entropy of activation and pre-exponential factor are presented in Table- 4 . The negative values of $\Delta S$ indicate that the activated 


\begin{tabular}{|c|c|c|c|c|c|c|c|c|c|}
\hline \multicolumn{10}{|c|}{$\begin{array}{c}\text { TABLE-4 } \\
\text { KINEIC AND THERMODYNAMIC PARAMETERS }\end{array}$} \\
\hline \multirow[b]{2}{*}{ Compound } & \multicolumn{3}{|c|}{ Stage-1 } & \multicolumn{3}{|c|}{ Stage-2 } & \multicolumn{3}{|c|}{ Stage-3 } \\
\hline & $\begin{array}{c}\mathrm{Ea} \\
(\mathrm{kJ} / \mathrm{mol})\end{array}$ & $\mathrm{A}\left(\mathrm{s}^{-1}\right)$ & $\underset{(\mathrm{kJ} / \mathrm{mol})}{\Delta \mathrm{S}}$ & $\begin{array}{c}\mathrm{Ea} \\
(\mathrm{kJ} / \mathrm{mol})\end{array}$ & $\mathrm{A}\left(\mathrm{s}^{-1}\right)$ & $\begin{array}{c}\Delta \mathrm{S} \\
(\mathrm{kJ} / \mathrm{mol})\end{array}$ & $\begin{array}{c}\mathrm{Ea} \\
(\mathrm{kJ} / \mathrm{mol})\end{array}$ & $A\left(s^{-1}\right)$ & $\begin{array}{c}\Delta \mathrm{S} \\
(\mathrm{kJ} / \mathrm{mol})\end{array}$ \\
\hline$\left[\mathrm{Ni}(\mathrm{mbt})_{2}(\mathrm{pyr})_{2}\right]$ & 83.26 & 158.08 & -206.19 & 470.95 & $1.93 \times 10^{-17}$ & 80.55 & 134.25 & 48.70 & -219.75 \\
\hline$\left[\mathrm{Ni}(\mathrm{mbt})_{2}(\mathrm{amp})_{2}\right]$ & 130.05 & 3513.69 & -181.84 & 193.93 & 232416.3 & -148.0 & 128.32 & 16.11 & -230.36 \\
\hline$\left[\mathrm{Ni}(\mathrm{mbt})_{2}(\mathrm{pyz})\right]_{\mathrm{n}}$ & 115.55 & 6008.71 & -176.13 & 235.45 & $1.02 \times 10^{-7}$ & -116.55 & 58.14 & 0.13 & -270.14 \\
\hline$\left[\mathrm{Ni}(\mathrm{mbt})_{2}(\text { bipy })\right]_{\mathrm{n}}$ & 372.30 & $2.61 \times 10^{14}$ & -27.20 & 62.71 & 1046434 & -246.94 & 54.27 & 0.19 & -265.44 \\
\hline$\left[\mathrm{Ni}(\mathrm{mbt})_{2}(\text { azpy })\right]_{\mathrm{n}}$ & 164.51 & 32173.13 & -164.10 & 127.05 & 131.69 & -211.23 & 256.16 & 294790.7 & -148.10 \\
\hline
\end{tabular}

complexes have more ordered structure than the reactants and the reactions are slower than the normal ${ }^{27,28}$. However we could not identify any definite trend in the values of $\mathrm{E}_{\mathrm{a}}$ and $\Delta \mathrm{S}$. The correlation coefficients obtained for the nine forms of equation proposed by Satava ${ }^{29}$, it is evident that in most of the cases it obey random nucleation, one nucleus on each particle, obeying Mampel equation ${ }^{30,31}$. The proposed structures for the adducts are given in Fig. 6.

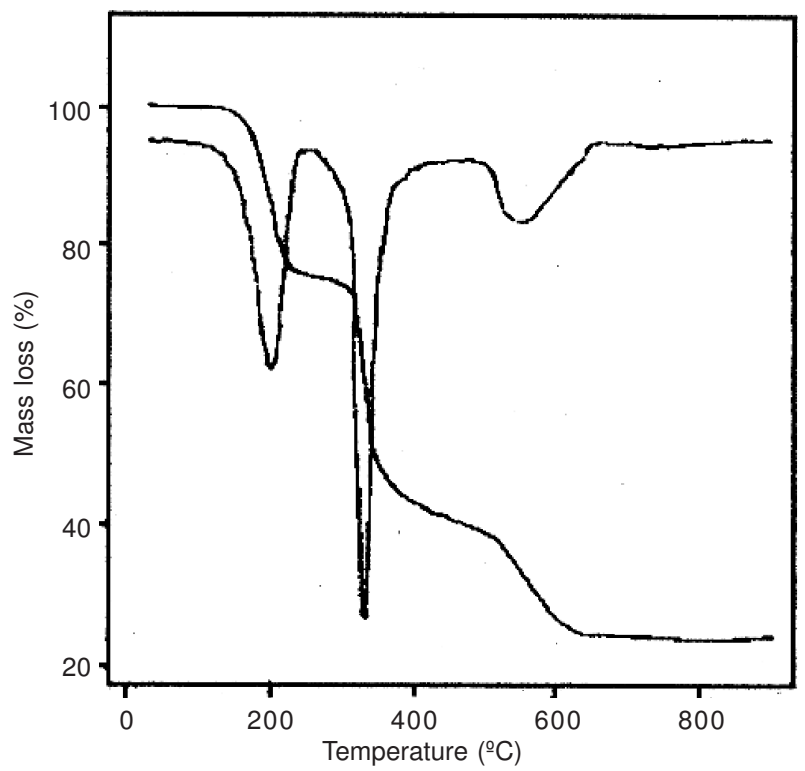

Fig. 1. Thermoanalytical (TG/DTG) curve of $\left[\mathrm{Ni}(\mathrm{mbt})_{2}(\mathrm{pyr})_{2}\right]$

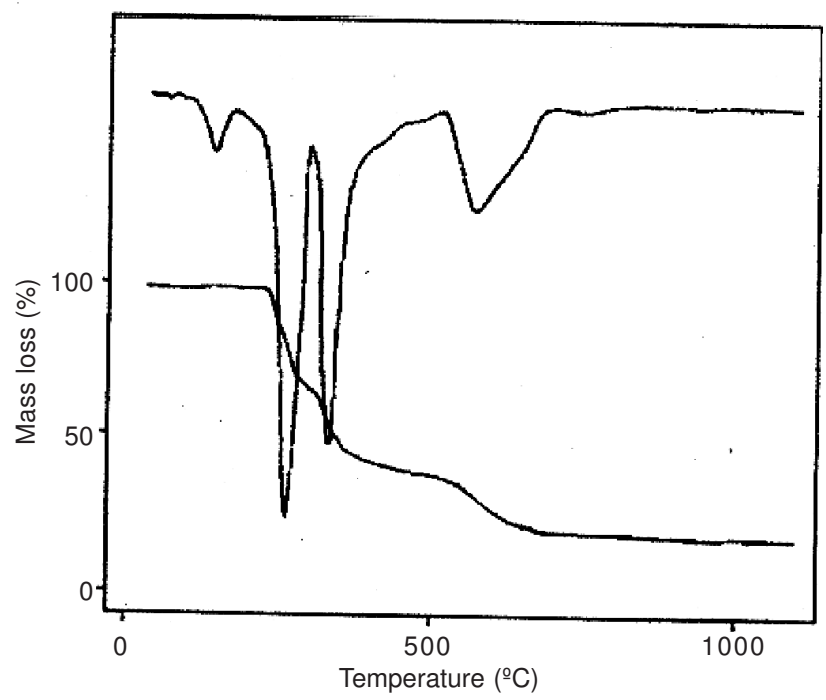

Fig. 2. Thermoanalytical (TG/DTG) curve of $\mathrm{Ni}(\mathrm{mbt})_{2}(\mathrm{amp})_{2}$

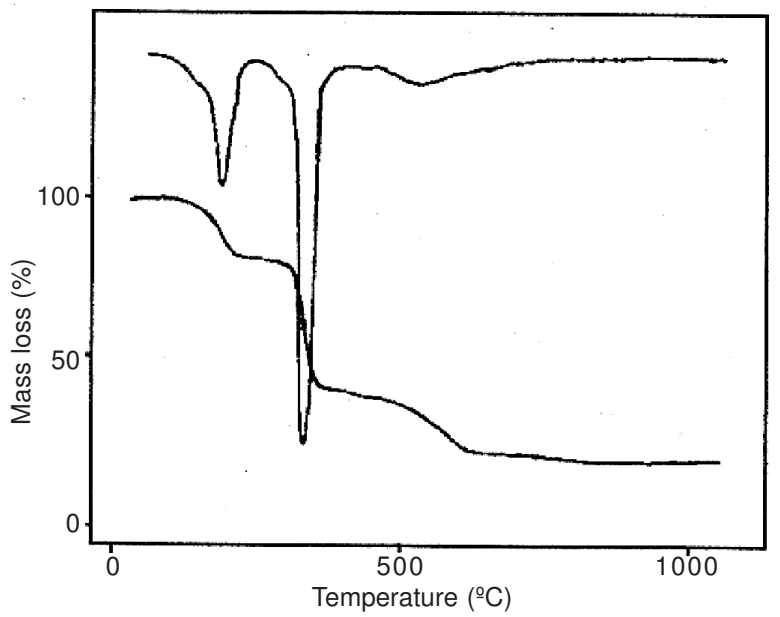

Fig. 3. Thermoanalytical (TG/DTG) curve of $\left[\mathrm{Ni}(\mathrm{mbt})_{2}(\mathrm{pyz})\right]_{\mathrm{n}}$

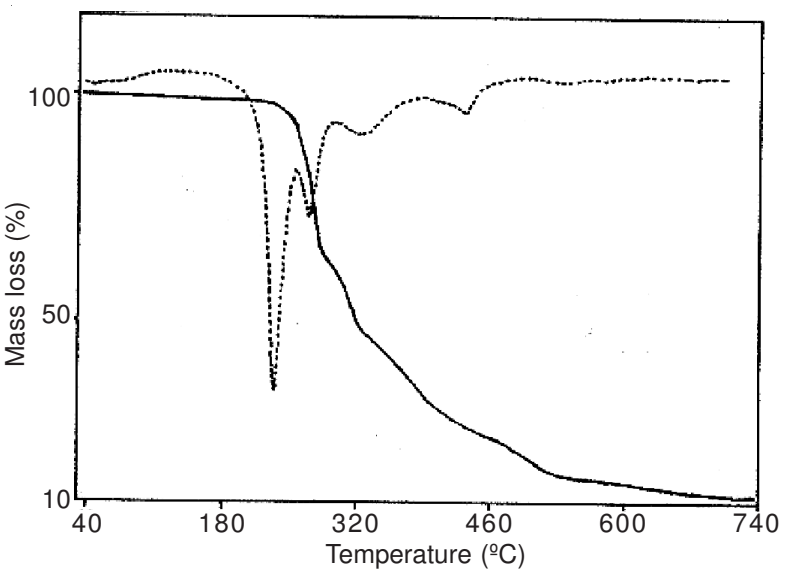

Fig. 4. Thermoanalytical (TG/DTG) curve of $\left[\mathrm{Ni}(\mathrm{mbt})_{2}(\text { bipy })\right]_{\mathrm{n}}$

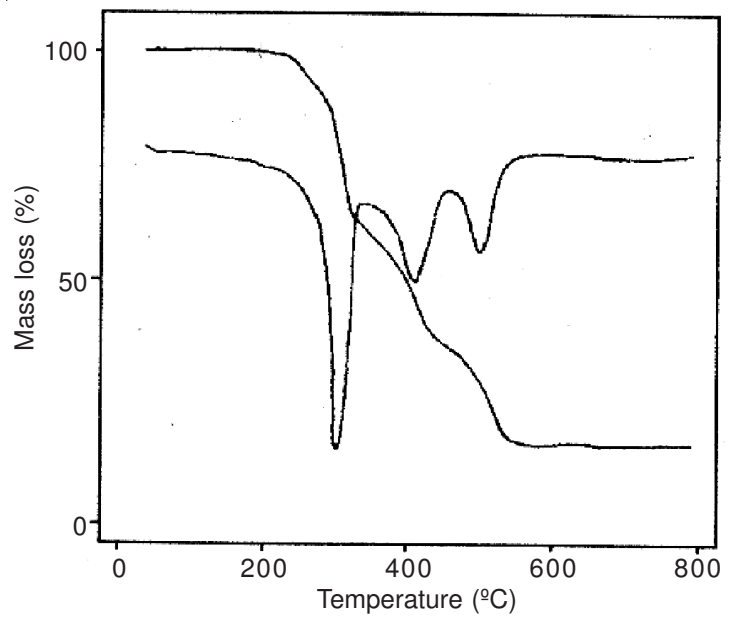

Fig. 5. Thermoanalytical (TG/DTG) curve of $\left[\mathrm{Ni}(\mathrm{mbt})_{2}(\text { azpy })\right]_{\mathrm{n}}$ 

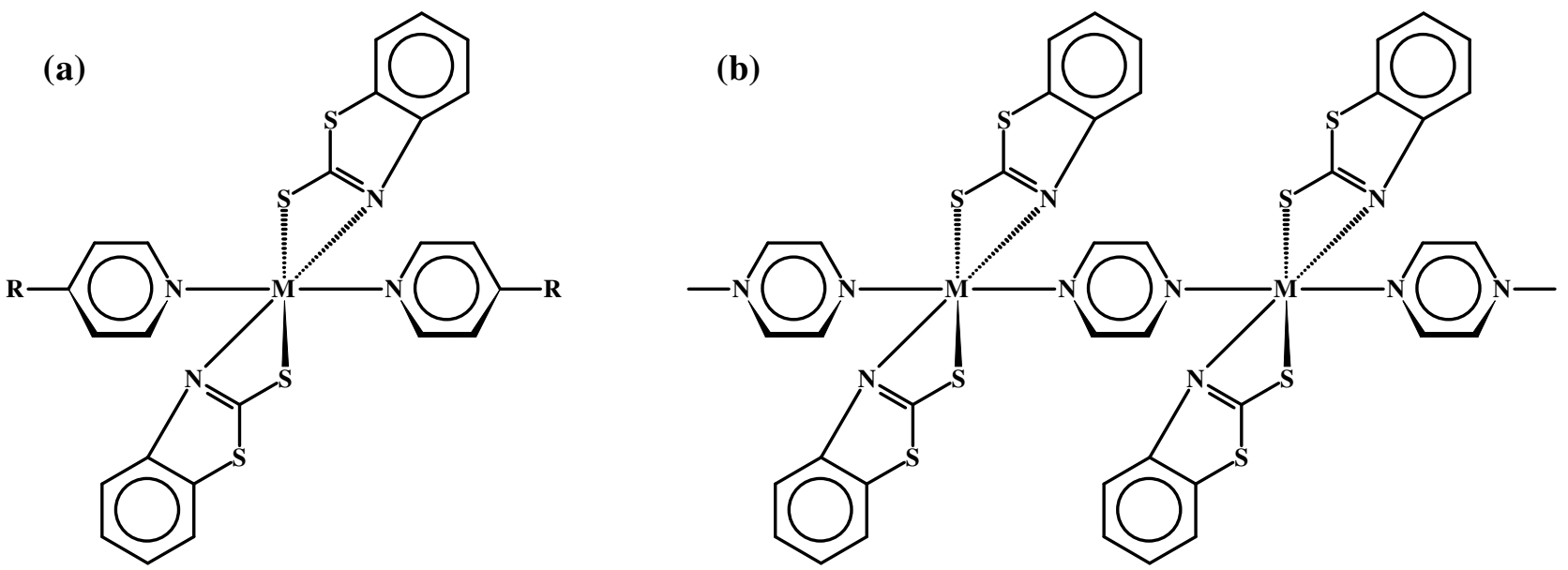

Fig. 6. Proposed structure of Lewis base adducts of $\left.\mathrm{Ni}(\mathrm{mbt})_{2} ; \mathrm{a}\right)$ Monomeric; $\left[\mathrm{Ni}(\mathrm{mbt})_{2}(\mathrm{pyr})_{2}\right]$ if $\mathrm{R}=\mathrm{H}$ and $\left[\mathrm{Ni}(\mathrm{mbt})_{2}(\mathrm{amp})_{2}\right]$ if $\left.\mathrm{R}=\mathrm{NH}_{2} ; \mathrm{b}\right)$ Polymeric; $\left[\mathrm{Ni}(\mathrm{mbt})_{2}(\mathrm{pyz})\right]_{\mathrm{n}},\left[\mathrm{Ni}(\mathrm{mbt})_{2}(\text { bipy })\right]_{\mathrm{n}}$ and $\left[\mathrm{Ni}(\mathrm{mbt})_{2}(\mathrm{azpy})\right]_{\mathrm{n}}$

\section{Conclusion}

The heteroleptic monomeric and polymeric Lewis base adducts of bis-[2-mercaptobenzothiazolatonickel(II)] (with different metal-metal bond lengths) were synthesized by coordination sphere expansion method and characterized using various physico-chemical methods. They have a trans-octahedral structure, thermally stable but yield back the parent four coordinated species on slow heating in most of the cases.

\section{REFERENCES}

1. J. Metz, G. Pawlowski and M. Hanack, Z. Naturforsh, 38B, 378 (1983).

2. O. Schnieder and M. Hanack, Angew. Chem. Int. Ed. Engl., 19, 392 (1980).

3. O. Schnieder and M. Hanack, Angew. Chem. Int. Ed. Engl., 21, 79 (1982).

4. O. Schnieder and M. Hanack, Chem. Ber, 116, 2088 (1983).

5. O. Schnieder, J. Metz and M. Hanack, Mol. Cryst. Liq. Cryst., 81, 273 (1982).

6. J. Metz, O. Schnieder and M. Hanack, Sprectrochim. Acta A, 38, 1265 (1982).

7. C.W. Dirk, T. Inabe, K.F. Schoch Jr. and T.J. Marks, J. Am. Chem. Soc., 105, 1539 (1983).

8. T. Inabe, J.G. Gaudiello, M.K. Moguel, J.W. Lyding, R.L. Burton, W.J. McCarthy, C.R. Kannewurf and T.J. Marks, J. Am. Chem. Soc., 108, 7595 (1986).

9. K. Fischer and M. Hanack, Chem. Ber., 116, 1860 (1983).

10. J.E. Maskasky and M.E. Kenney, J. Am. Chem. Soc., 95, 1443 (1973).

11. S. Banerji, R.E. Bryne and S.E. Livingstone, Transition Met. Chem., 7, 5 (1982).
12. M.F. El-Shazly, T. Salem, M.A. Sayed and S. Hedemy, Inorg. Chim. Acta, 29, 155 (1978).

13. J.P. Lawray, M. Tourrel-Paggis, J.F. Lispsker, V. Marvand and C. Joachin, Inorg. Chem., 30, 1033 (1992).

14. E.V. Brown and G.R. Granneman, J. Am. Chem. Soc., 97, 621 (1975).

15. M. Kuran, Coll. Czech. Chem. Commun., 37, 36 (1936).

16. A.B.P. Lever, Inorganic Electronic Spectroscopy, Elsevier, Amsterdam, 534 (1968).

17. Silverstein, Bassler and Morril, Spectroscopic Identification of Organic Compounds, John Wiley and Sons. Inc., edn. 5th

18. K. Nakamoto, Infrared and Raman Spectroscopy of Inorganic and Coordination Compounds, John Wiley and Sons. New York, edn. 4 (1986).

19. A.B.P. Lever, J. Lewis and R.S. Nyhom, Nature, 58, 189 (1961).

20. A.B.P. Lever, J. Lewis and R.S. Nyhom, J. Chem. Soc., 1235 (1962).

21. A.B.P. Lever, J. Lewis and R.S. Nyhom, J. Chem. Soc., 3156 (1963).

22. A.B.P. Lever, J. Lewis and R.S. Nyhom, J. Chem. Soc., 5042 (1963).

23. R.S. Drago, Physical Methods in Chemistey, Saunders, Philadelphia (1969).

24. J.A. Dean, Lange 's Hand Book of Chemistry, McGraw Hill Book Co. New York, edn. 13, 5.18-5.60 (1972).

25. W.W. Wendlandt, Thermal Analysis, Wiley-Interscience, New York, edn. 3 (1986).

26. A.W. Coats and J.P. Redfern, Nature, 201, 68 (1964).

27. A.A. Froast and R.G. Pearson, Kinetics and Mechanism, Wiley, New York (1961).

28. T. Gangadevi, K. Muraleedharan and M.P. Kannan, Thermochim. Acta, 146, 225 (1989).

29. V. Satava, Thermochim Acta, 2, 423 (1971).

30. C.G.R. Nair, S. Mathew and K.N. Ninan, Thermochim Acta, 150, 63 (1989).

31. S. Mathew, C.G.R. Nair and K.N. Ninan, Thermochim Acta, 144, 33 (1989). 